\title{
Optimal dietary approaches for prevention of type 2 diabetes: a life-course perspective
}

\author{
A. E. Buyken • P. Mitchell • A. Ceriello • J. Brand-Miller
}

Received: 4 August 2009 / Accepted: 18 November 2009/Published online: 5 January 2010

(C) Springer-Verlag 2009

\begin{abstract}
In recent years, several alternative dietary approaches, including high-protein and low-glycaemicload diets, have produced faster rates of weight loss than traditional low-fat, high-carbohydrate diets. These diets share an under-recognised unifying mechanism: the reduction of postprandial glycaemia and insulinaemia. Similarly, some food patterns and specific foods (potatoes, white bread, soft drinks) characterised by hyperglycaemia are associated with higher risk of adiposity and type 2
\end{abstract}

\footnotetext{
A. E. Buyken $(\bowtie)$

Nutrition and Health Unit, Research Institute of Child Nutrition, Heinstück 11,

44225 Dortmund, Germany

e-mail: buyken@fke-do.de

P. Mitchell

Centre for Vision Research, Department of Ophthalmology and Westmead Millennium Institute, University of Sydney, Sydney, NSW, Australia
}

\author{
A. Ceriello \\ University of Udine, \\ Udine, Italy
}

A. E. Buyken · J. Brand-Miller

Boden Institute of Obesity, Nutrition and Exercise,

University of Sydney,

Sydney, NSW, Australia diabetes. Profound compensatory hyperinsulinaemia, exacerbated by overweight, occurs during critical periods of physiological insulin resistance such as pregnancy and puberty. The dramatic rise in gestational diabetes and type 2 diabetes in the young may therefore be traced to food patterns that exaggerate postprandial glycaemia and insulinaemia. The dietary strategy with the strongest evidence of being able to prevent type 2 diabetes is not the accepted low-fat, high-carbohydrate diet, but alternative dietary approaches that reduce postprandial glycaemia and insulinaemia without adversely affecting other risk factors.

Keywords Diet · Glycaemia - Insulinaemia · Obesity Review · Type 2 diabetes
Abbreviations
GI Glycaemic index
GL Glycaemic load
NAFLD Non-alcoholic fatty liver disease

\section{Introduction}

At the start of this millennium, two large landmark studies showed that dietary intervention can prevent progression from impaired glucose tolerance to overt 
type 2 diabetes [1,2]. Both studies employed low-fat, high-carbohydrate diets (up to $30 \%$ of energy from fat, $10 \%$ from saturated fat) combined with physical activity to achieve weight loss. The findings have since been perceived as irrefutable evidence that low-fat, highcarbohydrate diets are the cornerstone for preventing type 2 diabetes among people at risk. In fact, these studies employed integrated diet, physical activity and lifestyle modifications, which resulted in weight loss. As such, the observed benefits cannot be directly attributed to the composition of the diet.

With regard to weight loss, several recent meta-analyses and reviews have concluded that low-carbohydrate, highprotein diets [3-5] and low-glycaemic-index (GI) or lowglycaemic-load (GL) diets [6, 7] may be more successful (or just as effective) as traditional low-fat, high-carbohydrate diets. Indeed, a high-fat Mediterranean-style diet was recently found to be more effective than a low-fat diet over a 2 year period [8]. Over the longer term, some studies suggest that these alternative dietary approaches are more effective for weight loss maintenance than low-fat, high-carbohydrate diets [8-11]. Although the differences may be considered 'modest', small increments in weight over time produce obesity, the single biggest modifiable risk factor for type 2 diabetes. In virtually all studies, alternative dietary approaches have been reported to be more effective than a conventional low-fat diet in optimising the cardiovascular outcomes of weight loss (e.g. improving dyslipidaemia) [5-7]. Taken together, this evidence argues that low-fat diets should not be the preferred dietary approach for persons at risk of developing diabetes.

The present review proposes that all alternative dietary approaches for preventing type 2 diabetes share an under-recognised unifying mechanism: the reduction of postprandial glycaemia and insulinaemia. In this scenario, any diet that facilitates this reduction will improve glucose and lipid metabolism, and relieve the burden on the beta cell. The least effective (or even most damaging) diet would be one that increased postprandial glycaemia and placed excess demands on beta cell function. These adverse effects are most detrimental for the growing number of individuals with features of the insulin resistance syndrome. Certain periods of life, including pregnancy and puberty, are also characterised by physiological insulin resistance $[12,13]$. In line with the 'early origins of health and disease' hypothesis, excessive postprandial glycaemia and insulinaemia during these critical windows could program a higher lifetime risk of developing obesity and type 2 diabetes.

\section{Carbohydrates, obesity and diabetes}

Since large-scale intervention studies analysing the impact of single dietary modifications on the risk of type 2 diabetes are not feasible, observational studies remain a major source of evidence for differential effects of carbohydrate quantity and quality on risk of type 2 diabetes. Epidemiological studies can be seen as 'natural experiments', but are hampered: (1) by the fact that selective under-reporting of nutritional intake may be related to the degree of overweight, which is the main modifiable risk factor for type 2 diabetes; and (2) by the conscious awareness of the relation between food intake and body weight, i.e. many overweight people are likely to under-report their food intake or to be currently dieting [14]. These limitations are of particular concern for cross-sectional studies on overweight, but less pertinent for prospective studies addressing disease outcomes such as type 2 diabetes. Due to the close alliance of obesity and type 2 diabetes, it nonetheless seems prudent to simultaneously consider the prospective epidemiological evidence linking diet to the subsequent development of both conditions.

Observational studies in adults almost unanimously suggest that high intakes of dietary fibre are effective in reducing the risk of obesity [15-17] and type 2 diabetes [18]. Recent studies focusing on whole grains in place of fibre, show similar benefits [19]. Unfortunately, high intakes of fibre or whole grains may also be markers of a healthier lifestyle [15]. In contrast, the epidemiological evidence for a role of dietary carbohydrate in the development of overweight or type 2 diabetes is much less consistent (see Textbox: Quantity and quality of dietary carbohydrate intake in association with risk of overweight and type 2 diabetes).

In most [17, 20-23], but not all studies [24], intakes of total carbohydrate (whether high or low) were not independently related to the development of obesity or type 2 diabetes. It is thus intriguing to consider that other components of total carbohydrate intake may be counteracting the benefits of a higher fibre intake. Highcarbohydrate choices vary considerably, not only in their content of dietary fibre or whole grains, but also in their 'glycaemic potency', i.e. the extent to which the available carbohydrate of a food exaggerates postprandial blood glucose excursions. The GI (a system of ranking foods for this purpose) is calculated as the blood glucose response to a $50 \mathrm{~g}$ ( or $25 \mathrm{~g}$ ) carbohydrate portion of food, expressed as a percentage of the same amount of carbohydrate from a reference food, either glucose or white bread [25]. Glycaemic load (GL $=$ quantity of carbohydrate $\times$ 


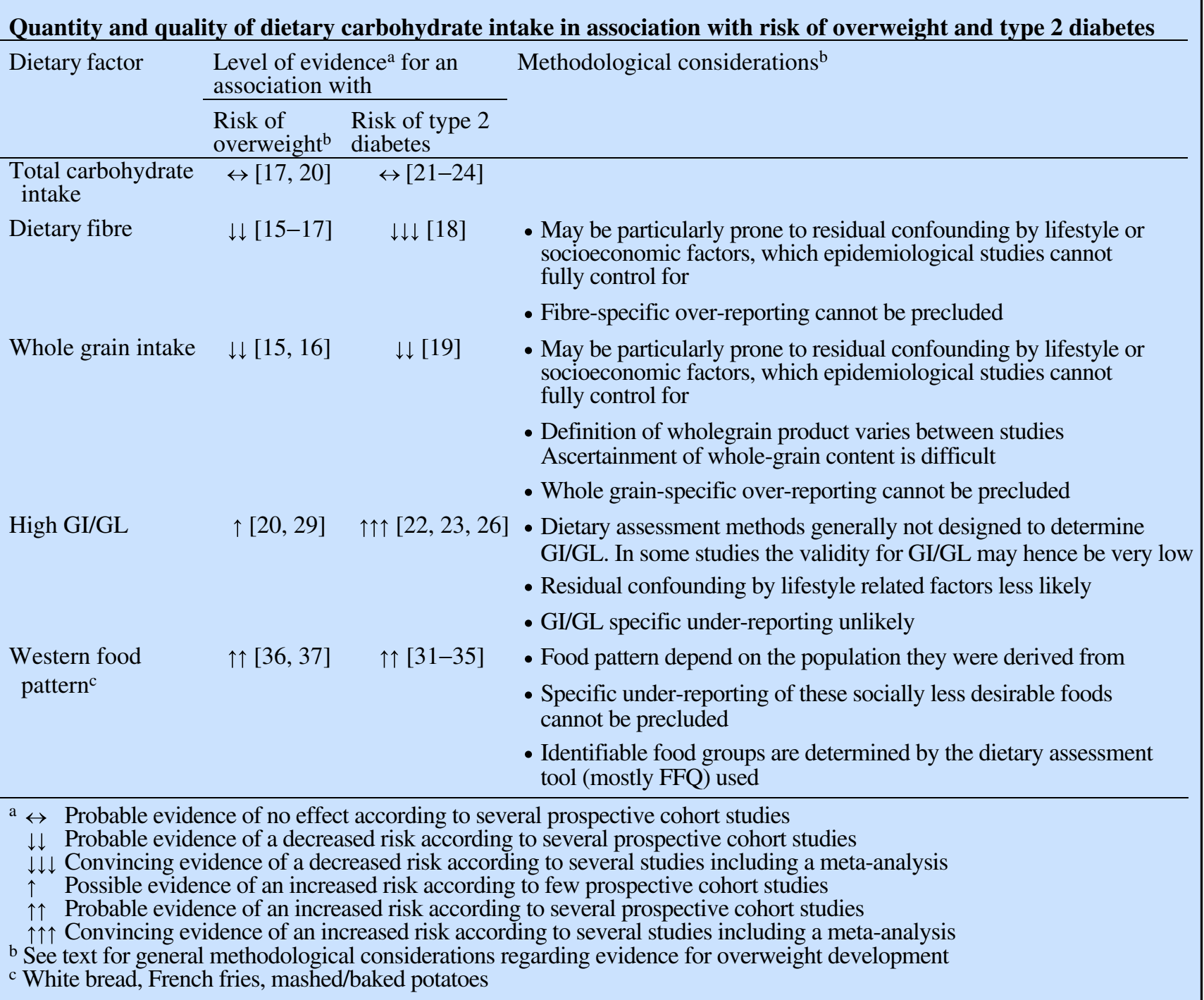

GI) has been proposed as a global indicator of the overall glucose response induced by a serving of a given food [21].

In a recent meta-analysis, GI and GL showed a clear relationship to the risk of type 2 diabetes [26], even though individual studies may not have shown significance $[27,28]$. Interestingly, in some studies, the highest relative risks $(>2)$ were observed among persons with a higher dietary GI or GL, and lower (cereal) fibre intake [22, 23]. Similarly, a higher dietary GI may be associated with subsequent adverse changes in BMI [20] or body weight, as well as body fat percentage and waist [20, 29], although only two studies have addressed this prospectively in adults $[20,29]$ (see Textbox: Quantity and quality of dietary carbohydrate intake in association with risk of overweight and type 2 diabetes).
Importantly, dietary GI or GL is not prone to confounding in the same way as fibre or whole grain intake. In fact, the tendency of many whole grains to have a high GI [30] works against a significant bias in the observed associations of GI with health outcomes.

Recent prospective studies have used exploratory (rather than hypothesis-based) dietary pattern analyses to identify food choices associated with the risk of developing type 2 diabetes or obesity. Although the identified patterns depend on the population from which they were derived, they are nevertheless similar, showing that increased risk of type 2 diabetes and overweight is associated with higher consumption of refined grains or white bread, ready-to-eat breakfast cereals, sugar-sweetened beverages, potatoes or French fries, and sweets or sweet bakery products; they also show a protective effect on the risk of these two conditions 
from other frequent carbohydrate choices such as fruits, vegetables, legumes, whole-meal or whole-grain bread and high-fibre breakfast cereals [31-37].

This body of evidence has contributed to recent public health initiatives directed at reducing soft drink consumption. However, such measures may need to be applied more broadly, since the adverse health consequences observed in dietary pattern analyses are likely to result from the combined effects of unfavourable carbohydrate choices, rather than from any single carbohydrate-providing food group. In fact, the choices associated with an increased risk of developing type 2 diabetes and overweight are generally known to yield higher postprandial glucose and insulin spikes, whereas those associated with a lower risk elicit lower postprandial responses [30].

\section{Carbohydrates and appetite}

In the traditional satiety hierarchy, protein is more satiating than carbohydrate and carbohydrate more satiating than fat. Part of the rationale for high-protein diets and highcarbohydrate diets as a means of weight loss is their ability to promote satiety and reduce total energy consumption $[38,39]$. However, when appearance, fibre and other factors are controlled for, more slowly digested, low-GI carbohydrate foods have been found to be more satiating than rapidly digested, high-GI carbohydrates [40], eliciting higher levels of satiety hormones such as cholecystokin [41]. An alternative hypothesis is that high postprandial glycaemia is followed by a 'dynamic decline' to levels below baseline in the following hours. This 'reactive hypoglycaemia' has been shown to increase hunger and may lead to a higher subsequent energy intake $[42,43]$. The counter-regulatory hormone response to restore euglycaemia also triggers an elevation of NEFA levels [43]. Higher ambient insulin levels may also reduce the oxidation of fat at rest and during exercise [44]. Hence, over the longer term, regular consumption of foods with a high GI may result in a shift from fat to glucose as the preferred metabolic fuel [45]. Resting energy expenditure is also lowered substantially on a low-fat, high-carbohydrate weight loss diet, while a low-GL diet lowers resting energy expenditure to a lesser degree [46].

In the context of conventional low-fat, high-carbohydrate diet, advice usually focuses on the use of fibre-rich foods without reference to their GI. However, most wholemeal breads and many 'wholegrain' flaked breakfast cereals also have a relatively high GI [30]. Thus, even if high fibre intake is achieved, such diets may produce higher daylong glycaemic and insulin profiles than high-fat or lowGI alternatives [47]. Traditional Mediterranean-type diets (characterised by higher fat and lower carbohydrate content), as well as low-carbohydrate and high-protein diets also reduce postprandial glycaemic and/or insulinaemic responses. This occurs despite the fact that these dietary approaches are not tailored specifically to affect postprandial metabolic responses [47-51]. It is thus conceivable that their higher effectiveness is partly attributable to metabolic adaptations similar to those seen on a low-GI or low-GL diet (Fig. 1).

\section{Carbohydrates and glucose homeostasis}

Glucose homeostasis plays a major role in the prevention of type 2 diabetes, weight gain and cardiovascular disease. In the Study to Prevent Non-Insulin-Dependent Diabetes Mellitus (STOP-NIDDM) trial, treatment with the $\alpha$-glucosidase inhibitor acarbose, a compound that specifically reduces postprandial hyperglycaemia, reduced the risk of type 2 diabetes [52], weight gain over time [52, 53] and cardiovascular disease [53]. The repeated challenge to glucose homeostasis induced by a low-fat, high-carbohydrate diet is of concern. Healthy, active individuals may adjust to the postprandial glucose challenge following a high-carbohydrate meal (commonly characterised as having a high GI) by increasing the insulin sensitivity of their peripheral tissues [54]. However, less active individuals must increase their insulin secretion in order to re-establish glucose homeostasis. In

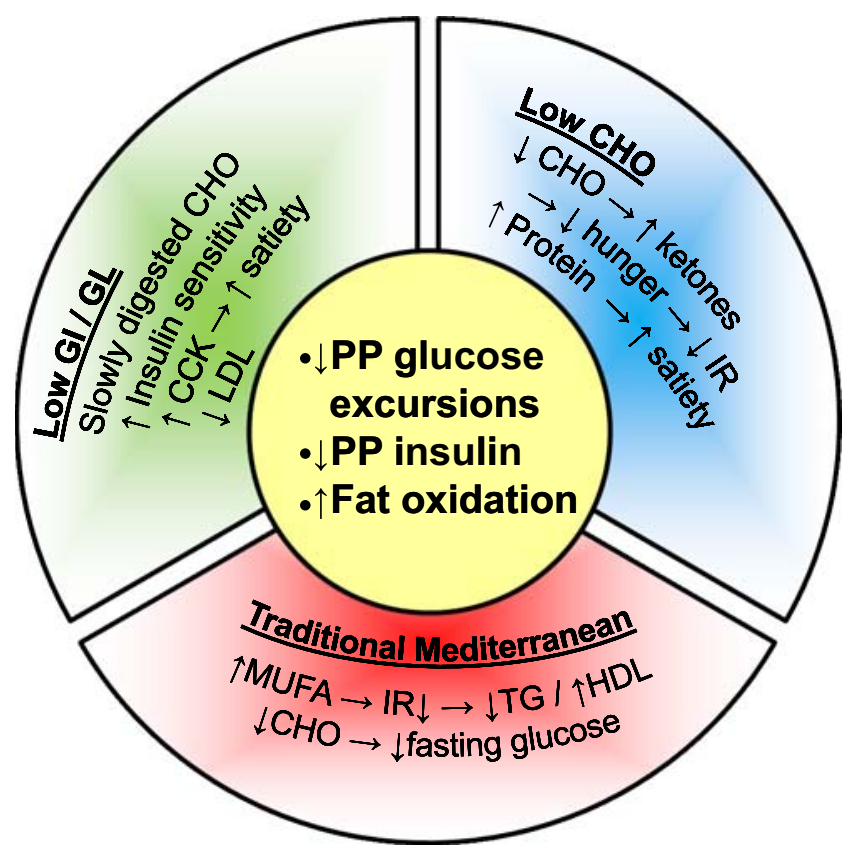

Fig. 1 Mechanisms of three popular alternative dietary strategies potentially relevant to the prevention of overweight and type 2 diabetes. Yellow shaded areas denote the proposed unifying mechanisms. CCK, cholecystokinin; CHO, carbohydrate; IR, insulin resistance; MUFA, monounsaturated fat; PP, postprandial; TG, triacylglycerol 
these people, adherence to the recommended highcarbohydrate diet may result in higher postprandial glycaemic and insulinaemic excursions and greater demands on beta cell function, which could eventually promote a more rapid development of type 2 diabetes (Fig. 2) and thereby an increased risk of other adverse health outcomes. In fact, compensatory hyperinsulinaemia when necessary to maintain the metabolic effects of insulin will also lead to an overstimulation of its nuclear effects, hence contributing to the progression of atherosclerosis and development of cancer [55].

Indeed, recent weight loss studies suggest that glucosetolerant persons with lower insulin secretion can successfully lose weight on either a low-fat, high-carbohydrate diet or an alternative dietary approach, whereas those who present with higher insulin secretion, i.e. those who may be insulin-resistant but still have good beta cell function are much more successful with dietary approaches targeting the reduction of postprandial glycaemia or insulinaemia, i.e. low-GI or GL diets [56, 57]. Animal studies also support the notion that the higher insulin secretion induced by highGI starch is associated with greater weight gain and disruption of beta cell architecture, while low-GI starch provides benefits [58].

Similarly, evidence for a greater effectiveness among more insulin-resistant persons is also evolving for other alternative dietary approaches. Among overweight, insulinresistant women, a high-protein diet was more successful in substantially improving waist circumference, and triacylglycerols and insulin levels, over 12 months than a highcarbohydrate diet [10]. In a large recent 2 year workplace trial, a Mediterranean-style diet produced not only more sustained weight loss in all participants than a low-fat, highcarbohydrate diet, but it also improved the fasting plasma glucose and insulin levels more favourably among persons with type 2 diabetes [8]. For patients with type 2 diabetes, a 6 month low-GI diet resulted in moderately lower $\mathrm{HbA}_{1 \mathrm{c}}$ levels, increased HDL-cholesterol levels and a tendency towards a higher body weight reduction than a high cereal fibre diet [59].

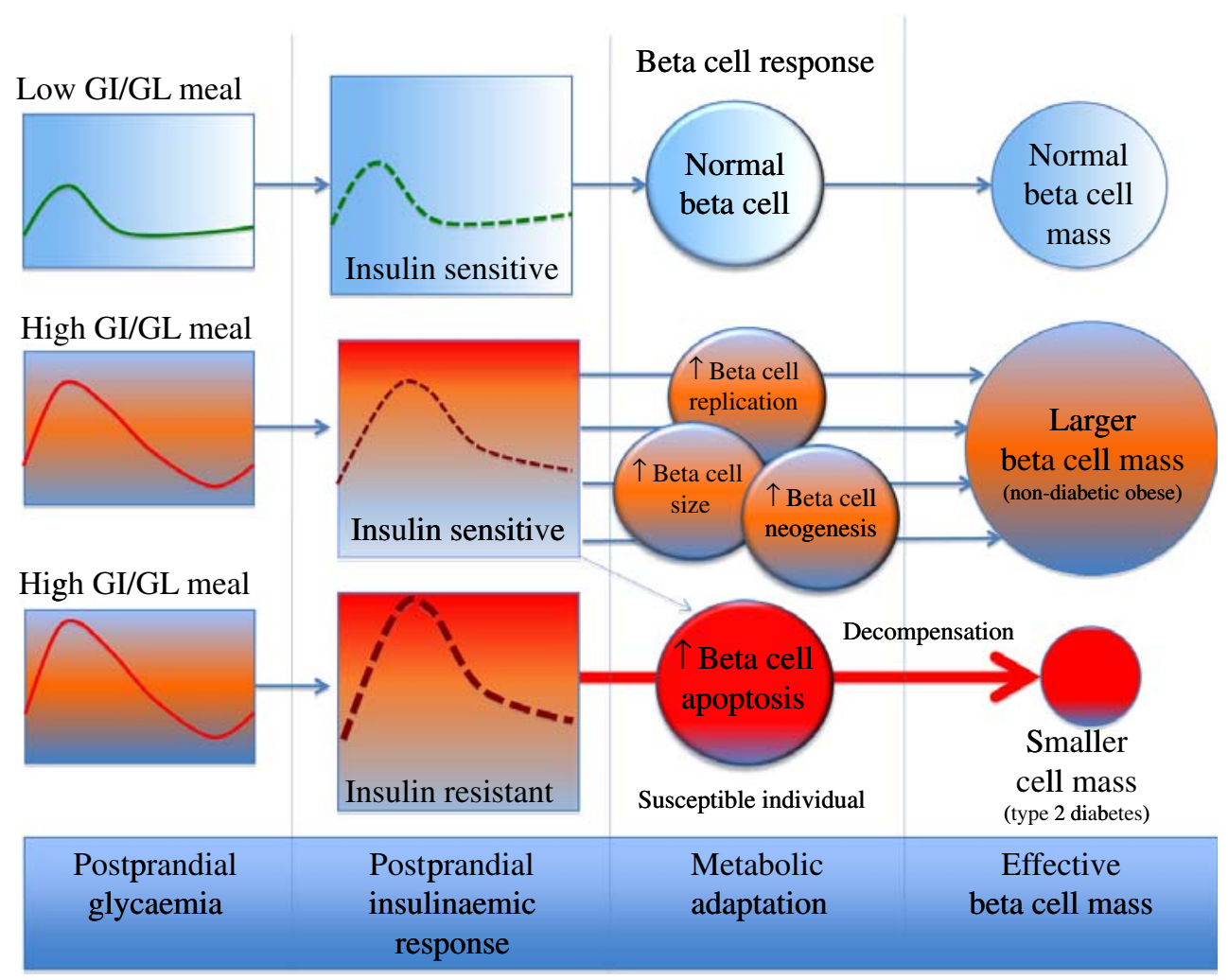

Fig. 2 A tenuous balance exists between insulin resistance and an effective beta cell mass. For the most part, beta cell mass adapts adequately to compensate for changes in the metabolic load. However, beta cells can be pushed too far in susceptible individuals. High-GI carbohydrates and high-GI diets can worsen insulin resistance and contribute to an overwhelming metabolic load. Eventually the beta cell mass fails to compensate for insulin resistance and type 2 diabetes ensues. This failure may be caused by a marked increase in beta cell apoptosis, probably induced by a combination of chronic postprandial hyperglycaemia and hyperlipidaemia, and/or certain cytokines that interfere with the signalling pathways that maintain normal beta cell growth and survival. Of all tissues, the beta cells in particular are especially sensitive to endoplasmic reticulum stress and to oxidative stress caused by high throughput through the mitochondrial chain. The net effect is a reduction in functional beta cell mass in the type 2 diabetic state. Information drawn from previously published work [119, 120] 


\section{Carbohydrates, serum lipids and hepatic lipogenesis}

There is concern that certain alternative dietary approaches have adverse effects on LDL-cholesterol levels and could therefore increase cardiovascular disease risk over the longer term. In fact, according to a meta-analysis of five weight loss trials, unrestricted low-carbohydrate diets produce more favourable changes in triacylglycerol and HDL-cholesterol than low-fat energy-restricted diets, but tend to increase LDL-cholesterol [5]. Since then, three large-scale weight loss interventions have confirmed the long-term benefits of alternative approaches for triacylglycerol and HDL-cholesterol levels $[8,9,60]$. Sustained adverse effects on LDL-cholesterol were observed in only one trial [60].

With regard to high-protein diets, two recent weight loss trials reported reductions in triacylglycerol levels, which were not accompanied by increases in LDL-cholesterol when carbohydrates were selected from low-GI foods $[10,51]$. This observation is in line with a meta-analysis of six weight loss interventions, which reported lower LDLcholesterol levels under unrestricted low-GI/GL diets when compared with conventional energy-restricted low-fat diets [7]. Furthermore, a meta-regression of 32 intervention trials revealed that reduced fasting triacylglycerol was related to reductions in GL after adjustment for total fat intake [6]. Similarly, beneficial effects on serum triacylglycerol, HDL-cholesterol and LDL-cholesterol levels were found in a meta-analysis of 60 studies analysing the replacement of carbohydrate by mono-unsaturated fat [61]. These broad benefits were recently confirmed in a 2-year intervention using a Mediterranean-style diet in patients with the metabolic syndrome [62].

Favourable effects of all alternative dietary strategies on the atherogenic dyslipidaemia commonly associated with the metabolic syndrome, i.e. on triacylglycerol and HDL-cholesterol, may also extend to the prevention of hepatic fat accumulation [63]. Non-alcoholic fatty liver disease (NAFLD) is increasingly recognised as a comorbid condition in the pathogenesis of type 2 diabetes mellitus [64]. Although multiple mechanisms are involved, chronic hyperglycaemia and hyperinsulinaemia are considered to play a key role, leading to enhanced glucose uptake by the liver, where glucose is converted to triacylglycerol via de novo lipogenesis, and contributing to excessive lipid storage [64]. In insulin resistance, dietary strategies causing marked postprandial elevations of blood glucose and NEFA could thus contribute to excessive hepatic lipogenesis [63]. In fact, in a crosssectional evaluation of healthy middle-aged Italians, highGI dietary habits were associated with high-grade liver steatosis, particularly in insulin-resistant participants [65]. In a 6 month intervention trial, a low-carbohydrate ketogenic diet resulted in a better lipid profile and clearly improved steatosis and inflammation in liver biopsies in comparison to a conventional low-fat diet [66]. Finally, a post hoc analysis of a 1 year weight loss trial conducted in middle-aged obese Israeli patients with type 2 diabetes indicated that a Mediterranean diet reduced alanine aminotransferase levels (a biomarker for NAFLD) to a larger extent than a conventional low-fat diet [67].

\section{Carbohydrates, oxidative stress, inflammation and haemostasis}

Oxidative stress, inflammation and haemostasis are emerging risk factors for the development of type 2 diabetes. Some evidence suggests that insulin resistance is a protective mechanism, which is an appropriate cellular response to nutrient excess and overproduction of mitochondrial superoxide [68]. Recurrent hyperglycaemia results in overproduction of reactive free radical molecules and release of pro-inflammatory cytokines, which may in turn induce chronic low-grade inflammation, vascular damage and haemostasis. Naturally occurring antioxidants in food are able to counterbalance the acute and chronic effects of hyperglycaemia and high concentrations of NEFA [69]. Hence, dietary approaches that simultaneously reduce postprandial glycaemia and NEFA levels while contributing to the body's antioxidant defence mechanism could be expected to reduce the likelihood of inflammation.

Indeed, dietary GI influences inflammatory markers acutely and over the long term. In ten lean healthy individuals, nuclear factor-kappa-B activation and nitrotyrosine were substantially reduced in the $3 \mathrm{~h}$ following a low-GI breakfast, by comparison with a high-GI meal [70]. Further, low-GI diets were associated with reduced chronic inflammation in recent observational studies [71, 72] and long-term consumption of a diet low in GL resulted in significantly lower levels of high-sensitive C-reactive protein in healthy overweight adults [57].

Similar benefits were observed with Mediterranean-type diets: greater adherence was associated with lower levels of inflammatory [73] and oxidative stress markers [74]. In a two year randomised trial among persons at risk of type 2 diabetes, consumption of a Mediterranean-style diet resulted in a concurrent reduction of inflammatory markers and insulin resistance [62].

Finally, the effects of oxidative stress on haemostasis may be relevant to the development of type 2 diabetes. Four high-quality, randomised controlled trials provide direct evidence that diets with a low GI improve fibrinolysis independently of changes in weight or macronutrient composition [75-78]. Using a parallel study design, 
Ebbeling et al. [75] compared an unrestricted low-GL diet with a conventional low-fat diet in 23 obese young adults over 12 months. Thrombogenic potential as measured by plasminogen activator inhibitor-1 concentrations decreased $(-39.0 \%)$ in the experimental diet group, but increased $(33.1 \%)$ in the conventional diet group. Changes in weight, cholesterol concentrations, blood pressure and insulin sensitivity did not differ significantly between the groups.

\section{Early origins of obesity and diabetes}

Many adult-onset diseases including overweight and type 2 diabetes appear to have their origins in early life. Nutritional programming of diseases with later onset has been defined as 'the idea that stimuli or insults applied during critical or sensitive periods of early life can have lifetime consequences' [79]. Early life, i.e. from conception to late gestation and early postnatal life, is thought to be particularly critical for the development of overweight and type 2 diabetes in later life [79-81]. In addition, the periodicity of the adiposity rebound ( $\sim$ age 4-6 years, describing the nadir in the BMI growth curve before its continuous rise until adulthood) and adolescence have also been proposed as potentially critical periods for the development of later obesity [82].

Pregnancy and puberty are two potentially critical periods characterised by the development of a physiological insulin resistance. In the second and third trimester of pregnancy, both basal and postprandial insulin levels progressively increase. By the third trimester, basal glucose concentrations are lower, but postprandial glucose levels are elevated and remain elevated for longer. Maternal hepatic glucose production is also increased. This insulin resistance in part serves to re-direct glucose and nutrients away from maternal tissues to the fetus [12]. Puberty in turn is characterised by physiological insulin resistance due to a decrease in insulin sensitivity [13]. It is intriguing that dietary approaches tailored to reducing postprandial glycaemia and insulinaemia could be of particular relevance in these critical windows of time.

Since the Barker hypothesis was first formulated [83], much attention has been given to the observation that low birthweight predisposes to later insulin resistance as well as an increased risk of type 2 diabetes [84]. However, most children now born in developed countries do not have low birthweight. In fact, recent studies indicate a secular increase in birthweight and an accompanying increase in the number of children born large-for-gestational-age or macrosomic (birthweight $>4,000 \mathrm{~g}$ ) $[85,86]$. This phenom- enon has been attributed in part to increasing prevalence of gestational diabetes and pre-existing diabetes, and/or higher maternal pre-pregnancy BMI $[85,86]$. The increasing prevalence of gestational diabetes parallels that of obesity and type 2 diabetes [87]. Offspring exposed to maternal impaired glucose tolerance, diabetes or obesity in utero also have a higher risk of developing overweight or diabetes in later life $[80,81]$.

Observational evidence for a role of carbohydrate intake in the development of gestational glucose intolerance is emerging, though still controversial [88, 89]. One study found that higher GL and lower fibre intake in the prepregnancy diet was associated with an increased risk of developing gestational diabetes [88]. In a randomised controlled trial, the use of a low-GI dietary regimen in women diagnosed with gestational diabetes effectively halved the number who needed to use insulin, with no compromise in obstetric or fetal outcomes [90]. A recent meta-analysis of intervention studies on dietary advice in pregnancy to prevent gestational diabetes concluded that while a low-GI diet may be beneficial, more evidence is needed to substantiate this conclusion [91].

The Hyperglycemia and Adverse Pregnancy Outcome (HAPO) study reported a strong continuous association of maternal glycaemia with birthweight and neonatal adiposity for maternal glucose levels below those diagnostic of gestational diabetes [92]. In support, the major influence of maternal glycaemia on fetal growth was on adiposity in a contemporary UK birth cohort [81]. Dietary and lifestyle approaches to reduce glycaemia in all pregnant women are now recognised to be of paramount importance for both mother and child [81, 92]. Intervention studies in women without gestational diabetes suggest that a low-GI diet consumed during pregnancy will reduce the risk of a large infant $[93,94]$.

\section{Puberty and adolescence}

Both absolute and relative carbohydrate intake by adolescents has increased in Western countries [95, 96]. Since this increase has been characterised by higher consumption of carbohydrate choices from refined grains [95] and added sugars or sweets [96] without concomitant increases in fibre intakes [97], it can be assumed that the dietary GL has also increased [98]. With the development of puberty, the quality of dietary carbohydrate may deteriorate further, since adolescents generally consume more fast food and soft drinks than younger children [99]. While these secular and age changes may be well tolerated by normal-weight and physically active adolescents, they are likely to exacerbate the metabolic changes occurring during puberty among those entering adolescence with excess body weight and/or insulin 
resistance [100]. For example, in a recent study of healthy German adolescents, a higher dietary GI was associated with adverse changes in body composition only among those who were already overweight when they entered puberty [101].

Insulin sensitivity decreases during mid-puberty, but recovers to pre-pubertal levels by late puberty [100]. This physiological fall in insulin sensitivity during puberty is not related to body fat content [100] and is characterised by a decrease in peripheral insulin sensitivity and higher levels of fasting glucose and insulin, while increases in the acute insulin response are disproportionally low, i.e. the beta cells do not fully adapt to the decrease in insulin sensitivity [13]. Adolescents who require greater acute insulin responses to maintain their glucose tolerance (e.g. obese African-American adolescents) [102, 103] are at higher risk of developing type 2 diabetes [102] over a shorter timeframe than is commonly observed in adults [100]. In this context, a low-fat, high-carbohydrate diet, which induces disproportional insulin spikes, may be an inappropriate choice. Further, increased deposition of NEFAs in intramyocellular compartments is considered partly responsible for the pronounced insulin resistance observed in obese adolescents with impaired glucose tolerance [103]. In this risk population, a dietary regimen that favours 'reactive hypoglycaemia' will subsequently lead to an increase in circulating NEFA, perpetuating a vicious cycle that may eventually precipitate type 2 diabetes.

A low-fat, high-carbohydrate diet may not be harmful during some stages of life and/or metabolic conditions. Specifically, the metabolism of healthy normal-weight children [54] or the metabolism of physically active, insulin-sensitive individuals at most stages of life will probably be able to accommodate large carbohydrate challenges. However, as long-term eating habits are shaped during childhood, dietary advice for children and adolescents should consider the long-term health implications.

\section{The long-term perspective}

The search for optimal dietary strategies for prevention of type 2 diabetes should also encompass the need for maintenance of health and primary prevention of other chronic diseases. Ideally, these diets will suit metabolically healthy individuals, prevent progression to disease in those with sub-clinical metabolic derangements and be an optimal treatment for those with overt disease. Studies investigating the long-term effects of different dietary approaches on chronic diseases and allcause mortality rates are beginning to emerge (see Textbox: Advantages and limitations of common dietary strategies to prevent overweight or type 2 diabetes).
At present, the consumption of low-carbohydrate, high animal protein diets has been associated with increased risk of mortality over the long-term in three observational studies [104-106]. Furthermore, their relatively low fibre content suggests that the risk for some types of cancer may be increased [107]. Thus, caution is required.

Conversely, adverse effects have not been reported for the long-term consumption of Mediterranean-type diets, low-GI/ GL diets or low-carbohydrate, high vegetable protein diets. Instead, protection against cardiovascular disease is well established for Mediterranean-type diets [108]. Similar benefits are suggested for low-GI or GL diets $[25,26]$ and more recently also for high vegetable protein diets [109]. In addition, evidence is emerging that Mediterranean-type diets and low-GI or GL diets also offer modest protection against some cancers [26, 107, 110]. Greater adherence to the traditional Mediterranean diet is associated with a significant reduction in total mortality rates $[111,112]$. Future studies will need to address the long-term safety of lowcarbohydrate, high vegetable protein diets.

\section{Implementation: individualised dietary advice or public health approaches}

For the reasons outlined, a low-fat, high-carbohydrate diet may contribute to a vicious cycle particularly among those who have a genetic or programmed tendency to be insulinresistant, i.e. individuals with the metabolic syndrome, pregnant women and obese adolescents. Thus, in clinical practice, advice on healthy Mediterranean-style diets or lowGI/GL diets might be considered appropriate for those who would benefit most by preventing or delaying onset of gestational or type 2 diabetes. While physically active, insulin-sensitive individuals are less likely to benefit, the majority of middle-aged and older age groups are not sufficiently active and show a high prevalence of the metabolic syndrome and pre-diabetes. In view of the fact that adherence to healthy Mediterranean-style diets and low-GI/ GL diets is not detrimental to the remaining population groups, public health approaches should be considered.

\section{Diabetes prevention beyond the search for optimal dietary approaches}

Clearly an optimal dietary approach is only one of the cornerstones of effective prevention of type 2 diabetes. Strategies to address physical inactivity produce similar or additive benefits for risk reduction among those at risk of type 2 diabetes. In the Da Qing Study, interventions to enhance leisure time physical activity with or without a dietary intervention (to increase vegetable intake and to 


\begin{tabular}{|c|c|c|c|c|c|c|}
\hline 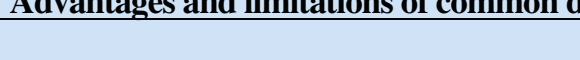 & & & Diet & ary strategies & & \\
\hline & $\begin{array}{l}\text { Low-fat } \\
\text { high-CHO }\end{array}$ & $\begin{array}{l}\text { Low-CHO } \\
\text { (e.g. Atkins) }\end{array}$ & $\begin{array}{l}\text { High-protein, } \\
\text { moderate CHO } \\
\text { (e.g. Zone) }\end{array}$ & $\begin{array}{l}\text { Low-CHO, high } \\
\text { vegetable protein } \\
\text { (e.g. ECO-Atkins) }\end{array}$ & $\begin{array}{l}\text { Mediterra- } \\
\text { nean }\end{array}$ & Low GI/GL \\
\hline Advantages $^{\mathrm{a}}$ & & & & & & \\
\hline $\begin{array}{l}\text { Facilitates appropriate intakes of } \\
\text { antioxidants, micronutrients and } \\
\text { dietary fibre }\end{array}$ & $\sqrt{ }$ & & & $\sqrt{ }$ & $\sqrt{ }$ & $\sqrt{ }$ \\
\hline Facilitates low energy density & $\sqrt{ }$ & & & & & $\sqrt{ }$ \\
\hline Facilitates optimal dietary fat quality & & & & $\sqrt{ }$ & $\sqrt{ }$ & $\sqrt{ }$ \\
\hline Beneficial effects on LDL-cholesterol & $\sqrt{ }$ & & & & $\sqrt{ }$ & $\sqrt{ }$ \\
\hline $\begin{array}{l}\text { Beneficial effects on HDL-cholesterol } \\
\text { and triacylglycerols }\end{array}$ & & $\sqrt{ }$ & $\sqrt{ }$ & ? & $\sqrt{ }$ & (b) \\
\hline $\begin{array}{l}\text { Lowers oxidative stress and low-grade } \\
\text { inflammation }\end{array}$ & & & & $?$ & $\sqrt{ }$ & $\sqrt{ }$ \\
\hline Lowers risk of cardiovascular disease & $(\sqrt{ })$ & $(\sqrt{ })$ & $(\sqrt{ })$ & $\sqrt{ }$ & $\sqrt{ }$ & $\sqrt{ }$ \\
\hline Lowers risk of certain cancer types & $\sqrt{ }$ & & & & $\sqrt{ }$ & $\sqrt{ }$ \\
\hline $\begin{array}{l}\text { Allows incorporation of all food } \\
\text { groups }^{\mathrm{b}}\end{array}$ & $\sqrt{ }$ & & & & $\sqrt{ }$ & $\sqrt{ }$ \\
\hline $\begin{array}{l}\text { Perceived palatability and social } \\
\text { desirability may facilitate long-term } \\
\text { adherence }^{\mathrm{b}}\end{array}$ & $\mathrm{m}$ & & & & $\sqrt{ }$ & $\sqrt{ }$ \\
\hline $\begin{array}{l}\text { Perceived environmental benefits may } \\
\text { facilitate long-term adherence }\end{array}$ & $(\sqrt{ })$ & & & $\sqrt{ }$ & $(\sqrt{ })$ & $(\sqrt{ })$ \\
\hline Limitations $^{\mathrm{c}}$ & & & & & & \\
\hline $\begin{array}{l}\text { Induces postprandial spikes in } \\
\text { glycaemia and insulinaemia }\end{array}$ & $\sqrt{ }$ & & & & & \\
\hline $\begin{array}{l}\text { Places excess demands on beta cell } \\
\text { secretion, may precipitate type } 2 \\
\text { diabetes in susceptible individuals }\end{array}$ & $\sqrt{ }$ & & & & & \\
\hline $\begin{array}{l}\text { May be associated with a higher } \\
\text { mortality risk }\end{array}$ & & $\sqrt{ }$ & $\sqrt{ }$ & & & \\
\hline Long-term effects on kidney function & & $?$ & $?$ & $?$ & & \\
\hline Long-term effects on bone metabolism & & $?$ & $?$ & $?$ & & \\
\hline References & $\begin{array}{l}{[107,117,} \\
118]\end{array}$ & $\begin{array}{l}{[5,8,9} \\
105,106]\end{array}$ & $\begin{array}{l}{[9,10,51} \\
104-106]\end{array}$ & {$[59,109]$} & $\begin{array}{c}{[61,62,} \\
73,74, \\
107,108]\end{array}$ & $\begin{array}{c}{[6,7,26,57} \\
71,72,107 \\
110]\end{array}$ \\
\hline
\end{tabular}

decrease alcohol and sugar) produced substantial reductions in type 2 diabetes incidence over the 6 year intervention [113]. These benefits were maintained even in the absence of further interventions: each of the three group-based lifestyle interventions (diet, exercise or their combination) produced sustained risk reductions, amounting to a $43 \%$ lower overall diabetes incidence in the 20 years of follow-up [114].

Psychosocial stress [115] and effort-reward imbalance [116] are also being increasingly recognised as important risk factors for type 2 diabetes and need to be addressed specifically in future integrated interventions on diet, physical activity and lifestyle.

\section{Conclusions}

Clinicians can do better than recommending a conventional low-fat, high-carbohydrate diet for prevention of type 2 diabetes. Most modern high-carbohydrate foods, whether high in fibre or not, place demands on beta cell function and/or insulin sensitivity that threaten glucose homeostasis. Profound compensatory hyperinsulinaemia occurs during periods of physiological insulin resistance such as pregnancy and puberty, and is exacerbated by overweight. The recent rise in gestational diabetes and type 2 diabetes in the young may therefore be traced to food patterns that exaggerate postprandial glycaemia 
and insulinaemia. The most evidence-based dietary strategy for prevention of type 2 diabetes includes alternative dietary approaches that reduce postprandial glycaemia and insulinaemia, without adverse effects on other risk factors. Healthy Mediterranean-style diets and low-GI/GL diets could now be recommended in place of conventional low-fat diets.

Acknowledgements A. E. Buyken received a 9 months' fellowship from the Heinrich-Hertz Stiftung of North-Rhine Westphalia, Düsseldorf, Germany.

Duality of interest J. Brand-Miller is Director of a not-for-profit GIbased food endorsement programme in Australia and manages the University of Sydney GI testing service; she is also co-author of 'The New Glucose Revolution' book series (London: Hodder and Stoughton). All other authors declare that there is no duality of interest associated with this manuscript.

\section{References}

1. Knowler WC, Barrett-Connor E, Fowler SE et al (2002) Reduction in the incidence of type 2 diabetes with lifestyle intervention or metformin. N Engl J Med 346:393-403

2. Tuomilehto J, Lindstrom J, Eriksson JG et al (2001) Prevention of type 2 diabetes mellitus by changes in lifestyle among subjects with impaired glucose tolerance. N Engl J Med 344:1343-1350

3. Halton TL, Hu FB (2004) The effects of high protein diets on thermogenesis, satiety and weight loss: a critical review. J Am Coll Nutr 23:373-385

4. Krieger JW, Sitren HS, Daniels MJ, Langkamp-Henken B (2006) Effects of variation in protein and carbohydrate intake on body mass and composition during energy restriction: a metaregression 1. Am J Clin Nutr 83:260-274

5. Nordmann AJ, Nordmann A, Briel M et al (2006) Effects of lowcarbohydrate vs low-fat diets on weight loss and cardiovascular risk factors: a meta-analysis of randomized controlled trials. Arch Intern Med 166:285-293

6. Livesey G, Taylor R, Hulshof T, Howlett J (2008) Glycemic response and health - a systematic review and meta-analysis: relations between dietary glycemic properties and health outcomes. Am J Clin Nutr 87:258S-268S

7. Thomas DE, Elliott EJ, Baur L (2007) Low glycaemic index or low glycaemic load diets for overweight and obesity. Cochrane Database Syst Rev, Issue 3. Art. no. CD005105. doi:10.1002/ 14651858.CD005105.pub2

8. Shai I, Schwarzfuchs D, Henkin Y et al (2008) Weight loss with a low-carbohydrate, Mediterranean, or low-fat diet. N Engl J Med 359:229-241

9. Gardner CD, Kiazand A, Alhassan S et al (2007) Comparison of the Atkins, Zone, Ornish, and LEARN diets for change in weight and related risk factors among overweight premenopausal women: the A TO Z Weight Loss Study: a randomized trial. JAMA 297:969-977

10. McAuley KA, Smith KJ, Taylor RW, McLay RT, Williams SM, Mann JI (2006) Long-term effects of popular dietary approaches on weight loss and features of insulin resistance. Int $J$ Obes (Lond) 30:342-349

11. Lejeune MP, Kovacs EM, Westerterp-Plantenga MS (2005) Additional protein intake limits weight regain after weight loss in humans. Br J Nutr 93:281-289

12. Butte NF (2000) Carbohydrate and lipid metabolism in pregnancy: normal compared with gestational diabetes mellitus. Am J Clin Nutr 71:1256S-1261S
13. Goran MI, Gower BA (2001) Longitudinal study on pubertal insulin resistance. Diabetes 50:2444-2450

14. van Dam RM, Seidell JC (2007) Carbohydrate intake and obesity. Eur J Clin Nutr 61(Suppl 1):S75-S99

15. Liu S, Willett WC, Manson JE, Hu FB, Rosner B, Colditz G (2003) Relation between changes in intakes of dietary fiber and grain products and changes in weight and development of obesity among middle-aged women. Am J Clin Nutr 78:920-927

16. Koh-Banerjee P, Franz M, Sampson L et al (2004) Changes in whole-grain, bran, and cereal fiber consumption in relation to 8-y weight gain among men. Am J Clin Nutr 80:1237-1245

17. Iqbal SI, Helge JW, Heitmann BL (2006) Do energy density and dietary fiber influence subsequent 5-year weight changes in adult men and women? Obesity (Silver Spring) 14:106-114

18. Schulze MB, Schulz M, Heidemann C, Schienkiewitz A, Hoffmann K, Boeing H (2007) Fiber and magnesium intake and incidence of type 2 diabetes: a prospective study and metaanalysis. Arch Intern Med 167:956-965

19. Priebe MG, van Binsbergen JJ, de Vos R, Vonk RJ (2008) Whole grain foods for the prevention of type 2 diabetes mellitus. Cochrane Database Syst Rev, Issue 1. Art. No. CD006061. doi:10.1002/14651858.CD006061.pub2

20. Ma Y, Olendzki B, Chiriboga D et al (2005) Association between dietary carbohydrates and body weight. Am J Epidemiol 161:359-367

21. Salmeron J, Ascherio A, Rimm EB et al (1997) Dietary fiber, glycemic load, and risk of NIDDM in men. Diabetes Care 20:545550

22. Schulze MB, Liu S, Rimm EB, Manson JE, Willett WC, Hu FB (2004) Glycemic index, glycemic load, and dietary fiber intake and incidence of type 2 diabetes in younger and middle-aged women. Am J Clin Nutr 80:348-356

23. Hodge AM, English DR, O’Dea K, Giles GG (2004) Glycemic index and dietary fiber and the risk of type 2 diabetes. Diabetes Care 27:2701-2706

24. Schulze MB, Schulz M, Heidemann C, Schienkiewitz A, Hoffmann K, Boeing H (2008) Carbohydrate intake and incidence of type 2 diabetes in the European Prospective Investigation into Cancer and Nutrition (EPIC)-Potsdam Study. Br J Nutr 99:11071116

25. Jenkins DJ, Wolever TM, Taylor RH et al (1981) Glycemic index of foods: a physiological basis for carbohydrate exchange. Am J Clin Nutr 34:362-366

26. Barclay AW, Petocz P, McMillan-Price J et al (2008) Glycemic index, glycemic load, and chronic disease risk - a meta-analysis of observational studies. Am J Clin Nutr 87:627-637

27. Mosdol A, Witte DR, Frost G, Marmot MG, Brunner EJ (2007) Dietary glycemic index and glycemic load are associated with high-density-lipoprotein cholesterol at baseline but not with increased risk of diabetes in the Whitehall II Study. Am J Clin Nutr 86:988-994

28. Sahyoun NR, Anderson AL, Tylavsky FA, Lee JS, Sellmeyer DE, Harris TB (2008) Dietary glycemic index and glycemic load and the risk of type 2 diabetes in older adults. Am J Clin Nutr 87:126-131

29. Hare-Bruun H, Flint A, Heitmann BL (2006) Glycemic index and glycemic load in relation to changes in body weight, body fat distribution, and body composition in adult Danes. Am J Clin Nutr 84:871-879

30. Atkinson FS, Foster-Powell K, Brand-Miller JC (2008) International tables of glycemic index and glycemic load values: 2008 . Diabetes Care 31:2281-2283

31. Hodge AM, English DR, O'Dea K, Giles GG (2007) Dietary patterns and diabetes incidence in the Melbourne Collaborative Cohort Study. Am J Epidemiol 165:603-610

32. Heidemann C, Hoffmann K, Spranger J et al (2005) A dietary pattern protective against type 2 diabetes in the European 
Prospective Investigation into Cancer and Nutrition (EPIC)Potsdam Study cohort. Diabetologia 48:1126-1134

33. McNaughton SA, Mishra GD, Brunner EJ (2008) Dietary patterns, insulin resistance, and incidence of type 2 diabetes in the Whitehall II Study. Diabetes Care 31:1343-1348

34. Montonen J, Knekt P, Harkanen T et al (2005) Dietary patterns and the incidence of type 2 diabetes. Am J Epidemiol 161:219-227

35. Schulze MB, Hoffmann K, Manson JE et al (2005) Dietary pattern, inflammation, and incidence of type 2 diabetes in women. Am J Clin Nutr 82:675-684

36. Schulz M, Nothlings U, Hoffmann K, Bergmann MM, Boeing H (2005) Identification of a food pattern characterized by high-fiber and low-fat food choices associated with low prospective weight change in the EPIC-Potsdam cohort. J Nutr 135:1183-1189

37. Schulze MB, Fung TT, Manson JE, Willett WC, Hu FB (2006) Dietary patterns and changes in body weight in women. Obesity (Silver Spring) 14:1444-1453

38. Paddon-Jones D, Westman E, Mattes RD, Wolfe RR, Astrup A, Westerterp-Plantenga M (2008) Protein, weight management, and satiety. Am J Clin Nutr 87:1558S-1561S

39. Rolls BJ (1995) Carbohydrates, fats, and satiety. Am J Clin Nutr 61:960S-967S

40. Holt SH, Miller JB (1995) Increased insulin responses to ingested foods are associated with lessened satiety. Appetite 24:43-54

41. Reynolds RC, Stockmann KS, Atkinson FS, Denyer GS, BrandMiller JC (2009) Effect of the glycemic index of carbohydrates on day-long $(10 \mathrm{~h})$ profiles of plasma glucose, insulin, cholecystokinin and ghrelin. Eur J Clin Nutr 63:872-878

42. Warren JM, Henry CJ, Simonite V (2003) Low glycemic index breakfasts and reduced food intake in preadolescent children. Pediatrics 112:e414. doi:10.1542/peds.112.5.e414

43. Ludwig DS, Majzoub JA, Al-Zahrani A, Dallal GE, Blanco I, Roberts SB (1999) High glycemic index foods, overeating, and obesity. Pediatrics 103:e26. doi:10.1542/peds.103.3.e26

44. Stevenson E, Williams C, Nute M (2005) The influence of the glycaemic index of breakfast and lunch on substrate utilisation during the postprandial periods and subsequent exercise. Br J Nutr 93:885-893

45. Ludwig DS (2002) The glycemic index: physiological mechanisms relating to obesity, diabetes, and cardiovascular disease. Jama 287:2414-2423

46. Pereira MA, Swain J, Goldfine AB, Rifai N, Ludwig DS (2004) Effects of a low-glycemic load diet on resting energy expenditure and heart disease risk factors during weight loss. Jama 292:2482 2490

47. Brynes AE, Mark Edwards C, Ghatei MA et al (2003) A randomised four-intervention crossover study investigating the effect of carbohydrates on daytime profiles of insulin, glucose, non-esterified fatty acids and triacylglycerols in middle-aged men. Br J Nutr 89:207-218

48. Paniagua JA, Gallego de la Sacristana A, Romero I et al (2007) Monounsaturated fat-rich diet prevents central body fat distribution and decreases postprandial adiponectin expression induced by a carbohydrate-rich diet in insulin-resistant subjects. Diabetes Care 30:1717-1723

49. Samaha FF, Iqbal N, Seshadri P et al (2003) A low-carbohydrate as compared with a low-fat diet in severe obesity. N Engl J Med 348:2074-2081

50. Arciero PJ, Gentile CL, Pressman R et al (2008) Moderate protein intake improves total and regional body composition and insulin sensitivity in overweight adults. Metabolism 57:757-765

51. McMillan-Price J, Petocz P, Atkinson F et al (2006) Comparison of 4 diets of varying glycemic load on weight loss and cardiovascular risk reduction in overweight and obese young adults: a randomized controlled trial. Arch Intern Med 166:14661475
52. Chiasson JL, Josse RG, Gomis R, Hanefeld M, Karasik A, Laakso M (2002) Acarbose for prevention of type 2 diabetes mellitus: the STOP-NIDDM randomised trial. Lancet 359:20722077

53. Chiasson JL, Josse RG, Gomis R, Hanefeld M, Karasik A, Laakso M (2003) Acarbose treatment and the risk of cardiovascular disease and hypertension in patients with impaired glucose tolerance: the STOP-NIDDM Trial. JAMA 290:486-494

54. Sunehag AL, Toffolo G, Treuth MS et al (2002) Effects of dietary macronutrient content on glucose metabolism in children. J Clin Endocrinol Metab 87:5168-5178

55. Wang CC, Goalstone ML, Draznin B (2004) Molecular mechanisms of insulin resistance that impact cardiovascular biology. Diabetes 53:2735-2740

56. Ebbeling CB, Leidig MM, Feldman HA, Lovesky MM, Ludwig DS (2007) Effects of a low-glycemic load vs low-fat diet in obese young adults: a randomized trial. Jama 297:2092-2102

57. Pittas AG, Das SK, Hajduk CL et al (2005) A low-glycemic load diet facilitates greater weight loss in overweight adults with high insulin secretion but not in overweight adults with low insulin secretion in the CALERIE Trial. Diabetes Care 28:2939-2941

58. Pawlak DB, Kushner JA, Ludwig DS (2004) Effects of dietary glycaemic index on adiposity, glucose homoeostasis, and plasma lipids in animals. Lancet 364:778-785

59. Jenkins DJ, Kendall CW, McKeown-Eyssen G et al (2008) Effect of a low-glycemic index or a high-cereal fiber diet on type 2 diabetes: a randomized trial. Jama 300:2742-2753

60. Sacks FM, Bray GA, Carey VJ et al (2009) Comparison of weight-loss diets with different compositions of fat, protein, and carbohydrates. N Engl J Med 360:859-873

61. Mensink RP, Zock PL, Kester AD, Katan MB (2003) Effects of dietary fatty acids and carbohydrates on the ratio of serum total to HDL cholesterol and on serum lipids and apolipoproteins: a meta-analysis of 60 controlled trials. Am J Clin Nutr 77:11461155

62. Esposito K, Marfella R, Ciotola M et al (2004) Effect of a Mediterranean-style diet on endothelial dysfunction and markers of vascular inflammation in the metabolic syndrome: a randomized trial. Jama 292:1440-1446

63. Zivkovic AM, German JB, Sanyal AJ (2007) Comparative review of diets for the metabolic syndrome: implications for nonalcoholic fatty liver disease. Am J Clin Nutr 86:285-300

64. Stefan N, Kantartzis K, Haring HU (2008) Causes and metabolic consequences of fatty liver. Endocr Rev 29:939-960

65. Valtuena S, Pellegrini N, Ardigo D et al (2006) Dietary glycemic index and liver steatosis. Am J Clin Nutr 84:136-142

66. Yancy WS Jr, Olsen MK, Guyton JR, Bakst RP, Westman EC (2004) A low-carbohydrate, ketogenic diet vs a low-fat diet to treat obesity and hyperlipidemia: a randomized, controlled trial. Ann Intern Med 140:769-777

67. Fraser A, Abel R, Lawlor DA, Fraser D, Elhayany A (2008) A modified Mediterranean diet is associated with the greatest reduction in alanine aminotransferase levels in obese type 2 diabetes patients: results of a quasi-randomised controlled trial. Diabetologia 51:1616-1622

68. Hoehn KL, Salmon AB, Hohnen-Behrens C et al (2009) Insulin resistance is a cellular antioxidant defense mechanism. Proc Natl Acad Sci USA 106:17787-17792

69. Ceriello A, Motz E (2004) Is oxidative stress the pathogenic mechanism underlying insulin resistance, diabetes, and cardiovascular disease? The common soil hypothesis revisited. Arterioscler Thromb Vasc Biol 24:816-823

70. Dickinson S, Hancock DP, Petocz P, Ceriello A, Brand-Miller J (2008) High-glycemic index carbohydrate increases nuclear factor-kappaB activation in mononuclear cells of young, lean healthy subjects. Am J Clin Nutr 87:1188-1193 
71. Du H, van der AD, van Bakel MM et al (2008) Glycemic index and glycemic load in relation to food and nutrient intake and metabolic risk factors in a Dutch population. Am J Clin Nutr 87:655-661

72. Levitan EB, Cook NR, Stampfer MJ et al (2008) Dietary glycemic index, dietary glycemic load, blood lipids, and Creactive protein. Metabolism 57:437-443

73. Chrysohoou C, Panagiotakos DB, Pitsavos C, Das UN, Stefanadis C (2004) Adherence to the Mediterranean diet attenuates inflammation and coagulation process in healthy adults: the ATTICA Study. J Am Coll Cardiol 44:152-158

74. Dai J, Jones DP, Goldberg J et al (2008) Association between adherence to the Mediterranean diet and oxidative stress. Am J Clin Nutr 88:1364-1370

75. Ebbeling CB, Leidig MM, Sinclair KB, Seger-Shippee LG, Feldman HA, Ludwig DS (2005) Effects of an ad libitum lowglycemic load diet on cardiovascular disease risk factors in obese young adults. Am J Clin Nutr 81:976-982

76. Jensen L, Sloth B, Krog-Mikkelsen I et al (2008) A lowglycemic-index diet reduces plasma plasminogen activator inhibitor-1 activity, but not tissue inhibitor of proteinases-1 or plasminogen activator inhibitor-1 protein, in overweight women. Am J Clin Nutr 87:97-105

77. Jarvi AE, Karlstrom BE, Granfeldt YE, Bjorck IE, Asp NG, Vessby BO (1999) Improved glycemic control and lipid profile and normalized fibrinolytic activity on a low-glycemic index diet in type 2 diabetic patients. Diabetes Care 22:10-18

78. Rizkalla SW, Taghrid L, Laromiguiere M et al (2004) Improved plasma glucose control, whole-body glucose utilization, and lipid profile on a low-glycemic index diet in type 2 diabetic men: a randomized controlled trial. Diabetes Care 27:1866-1872

79. Lucas A, Fewtrell MS, Cole TJ (1999) Fetal origins of adult disease - the hypothesis revisited. BMJ 319:245-249

80. Dabelea D, Mayer-Davis EJ, Lamichhane AP et al (2008) Association of intrauterine exposure to maternal diabetes and obesity with type 2 diabetes in youth: the SEARCH CaseControl Study. Diabetes Care 31:1422-1426

81. Ong KK, Diderholm B, Salzano G et al (2008) Pregnancy insulin, glucose, and BMI contribute to birth outcomes in nondiabetic mothers. Diabetes Care 31:2193-2197

82. Dietz WH (1994) Critical periods in childhood for the development of obesity. Am J Clin Nutr 59:955-959

83. Barker DJ (1990) The fetal and infant origins of adult disease. BMJ 301:1111

84. Whincup PH, Kaye SJ, Owen CG et al (2008) Birth weight and risk of type 2 diabetes: a systematic review. Jama 300:2886-2897

85. Kramer MS, Morin I, Yang H et al (2002) Why are babies getting bigger? Temporal trends in fetal growth and its determinants. J Pediatr 141:538-542

86. Schack-Nielsen L, Molgaard C, Sorensen TI, Greisen G, Michaelsen KF (2006) Secular change in size at birth from 1973 to 2003: national data from Denmark. Obesity (Silver Spring) 14:1257-1263

87. Dabelea D, Snell-Bergeon JK, Hartsfield CL, Bischoff KJ, Hamman RF, McDuffie RS (2005) Increasing prevalence of gestational diabetes mellitus (GDM) over time and by birth cohort: Kaiser Permanente of Colorado GDM Screening Program. Diabetes Care 28:579-584

88. Zhang C, Liu S, Solomon CG, Hu FB (2006) Dietary fiber intake, dietary glycemic load, and the risk for gestational diabetes mellitus. Diabetes Care 29:2223-2230

89. Saldana TM, Siega-Riz AM, Adair LS (2004) Effect of macronutrient intake on the development of glucose intolerance during pregnancy. Am J Clin Nutr 79:479-486

90. Moses RG, Barker M, Winter M, Petocz P, Brand-Miller JC (2009) Gestational diabetes; can a low glycemic index diet reduce the need for insulin? A randomised trial. Diabetes Care 32:996-1000

91. Tieu J, Crowther CA, Middleton P (2008) Dietary advice in pregnancy for preventing gestational diabetes mellitus. Cochrane Database Syst Rev, Issue 2. Art. No. CD006674. doi:10.1002/ 14651858.CD006674.pub2

92. Metzger BE, Lowe LP, Dyer AR et al (2008) Hyperglycemia and adverse pregnancy outcomes. N Engl J Med 358:1991-2002

93. Moses RG, Luebcke M, Davis WS et al (2006) Effect of a lowglycemic-index diet during pregnancy on obstetric outcomes. Am J Clin Nutr 84:807-812

94. Clapp JF 3rd (1998) Effect of dietary carbohydrate on the glucose and insulin response to mixed caloric intake and exercise in both nonpregnant and pregnant women. Diabetes Care 21 (Suppl 2):B107-B112

95. Alexy U, Sichert-Hellert W, Kersting M (2002) Fifteen-year time trends in energy and macronutrient intake in German children and adolescents: results of the DONALD Study. Br J Nutr 87:595-604

96. Nicklas TA, Elkasabany A, Srinivasan SR, Berenson G (2001) Trends in nutrient intake of 10-year-old children over two decades (19731994): the Bogalusa Heart Study. Am J Epidemiol 153:969-977

97. Alexy U, Kersting M, Sichert-Hellert W (2006) Evaluation of dietary fibre intake from infancy to adolescence against various references - results of the DONALD Study. Eur J Clin Nutr 60:909-914

98. Buyken AE, Dettmann W, Kersting M, Kroke A (2005) Glycaemic index and glycaemic load in the diet of healthy schoolchildren: trends from 1990 to 2002, contribution of different carbohydrate sources and relations to dietary quality. Br J Nutr 94:796-803

99. St-Onge MP, Keller KL, Heymsfield SB (2003) Changes in childhood food consumption patterns: a cause for concern in light of increasing body weights. Am J Clin Nutr 78:1068-1073

100. Goran MI, Ball GD, Cruz ML (2003) Obesity and risk of type 2 diabetes and cardiovascular disease in children and adolescents. J Clin Endocrinol Metab 88:1417-1427

101. Cheng G, Karaolis-Danckert N, Libuda L, Bolzenius K, Remer T, Buyken AE (2009) Relation of dietary glycemic index, glycemic load, and fiber and whole-grain intakes during puberty to the concurrent development of percent body fat and body mass index. Am J Epidemiol 169:667-677

102. Weiss R, Caprio S (2008) Obesity and T2DM in youth. Endocr Res 33:59-72

103. Weiss R, Dziura JD, Burgert TS, Taksali SE, Tamborlane WV, Caprio S (2006) Ethnic differences in beta cell adaptation to insulin resistance in obese children and adolescents. Diabetologia 49:571-579

104. Kelemen LE, Kushi LH, Jacobs DR Jr, Cerhan JR (2005) Associations of dietary protein with disease and mortality in a prospective study of postmenopausal women. Am J Epidemiol 161:239-249

105. Lagiou P, Sandin S, Weiderpass E et al (2007) Low carbohydrate-high protein diet and mortality in a cohort of Swedish women. J Intern Med 261:366-374

106. Trichopoulou A, Psaltopoulou T, Orfanos P, Hsieh CC, Trichopoulos D (2007) Low-carbohydrate-high-protein diet and long-term survival in a general population cohort. Eur J Clin Nutr 61:575-581

107. World Cancer Research Fund/American Institute for Cancer Research (2007) Food, nutrition, physical activity, and the prevention of cancer: a global perspective. AICR, Washington

108. de Lorgeril M, Salen P (2006) The Mediterranean-style diet for the prevention of cardiovascular diseases. Public Health Nutr 9:118-123

109. Halton TL, Willett WC, Liu S et al (2006) Low-carbohydratediet score and the risk of coronary heart disease in women. $\mathrm{N}$ Engl J Med 355:1991-2002

110. Mulholland HG, Cantwell MM, Anderson LA et al (2009) Glycemic index, carbohydrate and fiber intakes and risk of reflux 
esophagitis, Barrett's esophagus, and esophageal adenocarcinoma. Cancer Causes Control 20:279-288

111. Mitrou PN, Kipnis V, Thiebaut AC et al (2007) Mediterranean dietary pattern and prediction of all-cause mortality in a US population: results from the NIH-AARP Diet and Health Study. Arch Intern Med 167:2461-2468

112. Trichopoulou A, Costacou T, Bamia C, Trichopoulos D (2003) Adherence to a Mediterranean diet and survival in a Greek population. N Engl J Med 348:2599-2608

113. Pan XR, Li GW, Hu YH et al (1997) Effects of diet and exercise in preventing NIDDM in people with impaired glucose tolerance. The Da Qing IGT and Diabetes Study. Diabetes Care 20:537-544

114. Li G, Zhang P, Wang J et al (2008) The long-term effect of lifestyle interventions to prevent diabetes in the China Da Qing Diabetes Prevention Study: a 20-year follow-up study. Lancet 371:1783-1789

115. Heraclides A, Chandola T, Witte DR, Brunner EJ (2009) Psychosocial stress at work doubles the risk of type 2 diabetes in middle-aged women: evidence from the Whitehall II Study. Diabetes Care 32:2230-2235. doi:10.2337/dc09-0132

116. Kumari M, Head J, Marmot M (2004) Prospective study of social and other risk factors for incidence of type 2 diabetes in the Whitehall II Study. Arch Intern Med 164:1873-1880

117. Franz MJ, Bantle JP, Beebe CA et al (2002) Evidence-based nutrition principles and recommendations for the treatment and prevention of diabetes and related complications. Diabetes Care 25:148-198

118. Mann JI, de Leeuw I, Hermansen K et al (2004) Evidence-based nutritional approaches to the treatment and prevention of diabetes mellitus. Nutr Metab Cardiovasc Dis 14:373-394

119. Rhodes CJ (2005) Type 2 diabetes - a matter of beta-cell life and death? Science 307:380-384

120. Dickinson S, Colagiuri S, Faramus E, Petocz P, Brand-Miller JC (2002) Postprandial hyperglycemia and insulin sensitivity differ among lean young adults of different ethnicities. J Nutr $132: 2574-2579$ 